\title{
Inspection of Centrifugal Blower by Varying Different Blade Configuration using CFD
}

\author{
Mohammed Aslam Sohail, K.Venkateswarlu, Abdul Hafeez
}

\begin{abstract}
This examination points towards the advancement of an enhanced plan of a radiating blower comprising of different fan ribs, in light of execution appraisals looking like its inside parts. Different segments, for example, the outside cases and the turning fan ribs set in an assortment of working conditions, for example, fluctuating impeller speed and number of edges, are assessed mathematically and tentatively. Assessment depends on execution boundaries, including the delta and outlet pressures, stream rate, force, and intensity of the radial fan. The mathematical examination recommends that the blend of the different pivoting outline strategy and the standard $k-\varepsilon$ disturbance model was suitable for recreation of the inside stream qualities and for power forecast. The mathematical outcomes were contrasted and tests under deliberately planned trial conditions. Plan and displaying of Impeller and packaging has been completed in CATIA V5R21 and then the Calculation was imported to Ansys 16.0. By differing the quantity of fan ribs, the exhibition fluctuates practically nothing. Nonetheless, the FC fan ribs display the best exhibition in regards to their stream rate reaction and are related with most reduced force. The weight at the exit is diminished as the stream rate is expanded. Among all the fans, the FC fan would yield the most noteworthy stream rate.
\end{abstract}

Keywords: CFD, Impeller, $k-\varepsilon$, Torque, Pressure.

\section{INTRODUCTION}

The world interest for vitality is quickly expanding. We need vitality to warm our homes, to prepare our suppers, to travel and convey, and to control the workplaces or processing plants. Close by with the quick difference in vitality frameworks (e.g., crude coal burners to oil or as of late gas boilers and from focal warming framework to discrete warming framework), the apparatus markets of elite kettle framework have additionally been essentially expanded. It has been needing to grow broadly nature agreeable and high effectiveness hardware by considering at the same time both the slowly greater costs of bringing in vitality as per the exhaustion of non-renewable energy sources and the ecological issues, for example, air contamination and an Earth-wide temperature boost. As of late, the all-out world warming (particularly, gas-terminated) heater market was

Revised Manuscript Received on October 10, 2020.

* Correspondence Author

Mohammed Aslam Sohail*, MTech, Thermal Engineering, Mechanical Department, Gokaraju Rangaraju College of Engineering and Technology, Bachupally, Hyderabad

K. Venkateswarlu, Professor of Thermal Engineering, Mechanical Department, Gokaraju Rangaraju College of Engineering and Technology, Bachupally, Hyderabad

Abdul Hafeez, ME, Mechanical Department, Osmania University, Hyderabad

(C) The Authors. Published by Blue Eyes Intelligence Engineering and Sciences Publication (BEIESP). This is an open access article under the CC BY-NC-ND license (http://creativecommons.org/licenses/by-nc-nd/4.0/) assessed around 10 billion dollars and 12 million units in 2006 and expected to develop at a moderate rate throughout the following decades. The UK is the greatest market in both worth and volume terms, trailed by South Korea and Italy.

In a wide scope of modern and private home uses of vitality framework, the business of the boilers must cling to a market arranged methodology, intently depending on the logical and mechanical development in the public vitality and ecological approach under the direction of rebuilding the ventures, and item blend, production and offer of boilers so as to satisfy profoundly serious market need. One of the techniques to expand the effectiveness of the kettle is to accomplish a total burning, which not just builds the proficiency of a gas-terminated evaporator, yet in addition diminishes the creation of ecological contaminants. For complete burning in the evaporator, proper working conditions ought to be kept up, and this can be accomplished by expanding the ignition time and utilizing a suitable blend (for example stoichiometric blend) of air and fuel. Accordingly, it is vital to comprehend which modules and parts in the framework are exceptionally viable and intended for acquiring the best working conditions. One of the center segments in the heater is the diffusive fan, which is generally used to give air to the kettle to burning. Contingent upon the shape and size of these fans (for example fan ribs or impellers), the presentation of the kettle can be improved. In this manner, so as to acknowledge fan ribs with superior and effectiveness, a methodical plan approach must be taken at the model stage.

\section{LITERATURE REVIEW}

\section{CHRISTOPHER L. BANKS AND SEAN F. WU [7]}

Present the consequences of an examination of radiating blower commotions. Investigations on three unique kinds of blowers were directed to decide the significant clamor age instruments. The data consequently picked up has prompted an inventive clamor decrease strategy using a fixed, non-reaching change work. In these investigations a general commotion decrease of 3 to $5 \mathrm{~dB}$ was accomplished for all the blowers running at impeller speeds in the scope of 10 to 30 $\mathrm{m} / \mathrm{s}$. Likewise, a semi diagnostic model was created to foresee clamor spectra from dimensionally comparable radiating blowers. This model yielded an acoustic force relative to the fourth intensity of the blower speeds. Examinations of the determined and estimated clamor spectra from various blowers running under different velocities were additionally illustrated.

\section{G.H.Koopmann and W.Neise [5]}

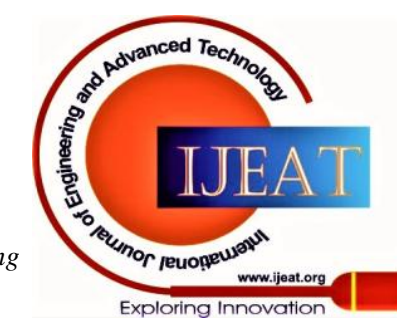




\section{Inspection of Centrifugal Blower by Varying Different Blade Configuration using CFD}

Adjusted radial blower by supplanting the cut-off of the look with a quarter-frequency resonator. The mouth of the resonator was shaped from a punctured plate which had a similar arch as the first cut-off area. Tuning of the resonator was accomplished by changing the length through a portable end plug.

Clamor estimations were made in anechoic partner ended delta and outlet conduits over a scope of streamlined stacking conditions and found that the degree of the decreases in the sharp edge passing recurrence tones in both the bay and outlet channels fluctuated with the direction of and the degree of open zone on the mouth puncture. They presented a splitter in the resonator mouth, generous decreases in both the gulf and outlet conduit were accomplished over an enormous scope of aerodynamic loading.

\section{Jianfeng Ma et al [8]}

Have concentrated on decrease of radiating blower whose impeller has equidistant forward-cleared cutting edges. The planned two new impellers with various sharp edge dividing and a test study was led. Both the fan's acro-dynamic execution and clamor were estimated and afterward the two upgraded impellers were contrasted and the first ones. He likewise broke down the impact of the commotion decrease strategy for a radial fan utilizing impellers with non-isometric forward - cleared edges.

\section{Chunxi et al. [11]}

Discovered that the addition of fan ribs in width with the keeping the size of volute (less freedom between fan ribs and volute) initiated the loss of hole stream and the increase of stream rate and weight, which expanded the pole force and sound weight level, while the productivity of fan ribs diminished. Obviously, the higher clamor level was brought about by the decreased fan ribs-volute hole.

\section{Q. Datong et.al [6]}

has given a Test concentrate on the clamor decrease of a modern forward-bended edges outward fan. They made a wide range of test tests to locate a decent impeller-volute coordinating to decrease the radiating fan commotion without lessening execution. The trial results show that great coupled adjustment decreases the fan clamor as well as could propel the fan execution.

\section{PrezeljJurij and Carudina Mirko [4]}

clarified about the recognizable proof of commotion sources on radial blower which was performed with an acoustic camera at the plan and off-plan activity conditions and presumed that the rotational clamor wins at the plan purpose of activity, and that the non-rotational commotion wins at off-plan activity The principle wellspring of clamor inside a pull unit can be credited to the efficiently created clamor, at the plan just as at off-plan activity.

\section{Renjing Cao and Jun HU[3]}

proposed a group configuration way to deal with accomplish a decent streamlined and acoustic exhibition of a ventilation framework and a serious estimation framework was received to test the streamlined and acoustic presentation of the unit which dependent on a line test rig with non-reflection acoustic limit and was intended to isolate the mechanical and wind current created commotion. This estimation gadget was situated at the ventilation room flexibly diffuser and the outcomes indicated that the group outward blower gives a higher mass stream rate and a lower sound weight level than mechanical ventilation framework.

\section{METHODOLOGY}

The math and physical limits of the issue can be characterized the utilization of PC helped design (CAD). From that point, records can be positively handled (cleaned off up) and the liquid degree (or liquid space) is separated. The degree involved by method of the liquid is separated into discrete cells (the work). The work can be uniform or non-uniform, based or unstructured, including a blend of hexahedral, tetrahedral, kaleidoscopic, pyramidal or polyhedral elements. The real demonstrating is depicted - for example, the conditions of smooth motion + enthalpy + radiation + species protection. Limit conditions are characterized. This includes determining the liquid conduct and houses at all bouncing surfaces of the liquid space. For brief inconveniences, the underlying circumstances likewise are characterized. The reenactment is begun and the conditions are settled iteratively as a consistent country or transient. At last a postprocessor is utilized for the investigation and perception of the subsequent arrangement.

Unearthly component technique is a limited component kind strategy. It requires the numerical issue (the halfway differential condition) to be strong in a weak equation. This is for the most part accomplished by utilizing duplicating the differential condition through a self-assertive investigate trademark and coordinating over the total region. Absolutely numerically, the test highlights are totally subjective - they have a place with a perpetual dimensional capacity region. Plainly an interminable dimensional trademark territory can't be spoken to on a discrete ghostly component work; that is the place the ghastly component discretization begins advanced. The most significant component is the choice of introducing and testing abilities. In a norm, low request FEM in 2D, for quadrilateral components the most well-known inclination is the bilinear investigate or adding highlight of the structure show style $\quad \mathrm{v}(\mathrm{x}, \mathrm{y})=\mathrm{ax}+\mathrm{by} \quad$ way of $+c x y+d v(x, y)=a x+v i a+c x y+d$. In an unearthly detail strategy, be that as it may, the adding and investigate abilities are chosen to be polynomials of a totally high request (by and large for example of the 10th request in CFD bundles). This ensures the quick combination of the technique. Moreover, productive reconciliation strategies must be utilized, for the explanation that assortment of incorporations to be executed in mathematical codes is huge. Accordingly, exorbitant request Gauss coordination quadrature are employed, on account that they gain the best exactness with the littlest assortment of calculations to be performed. At the time there are a couple of instructive CFD codes dependent on the phantom component strategy and some more noteworthy are by and by underneath progress, for the explanation that new time-venturing plans emerge inside the logical global. Good quality plagiarism software/ tool (Turnitin / authenticate) will be used to check similarity that would not be more than $20 \%$ including reference section.

Published By:

Blue Eyes Intelligence Engineering and Sciences Publication

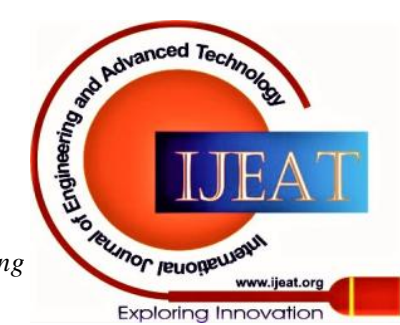


In the case of exclusion of references, it should be less than $5 \%$.

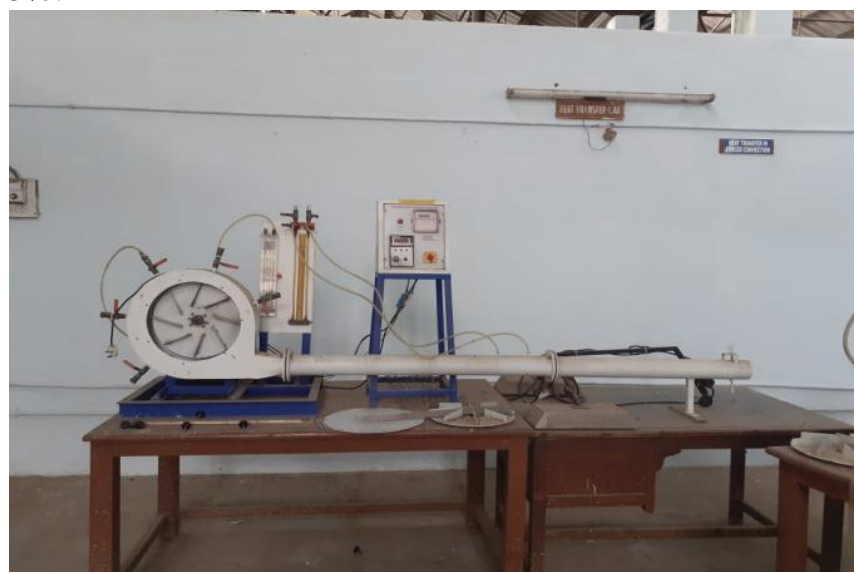

Fig 01: Experimental setup of Centrifugal Blower.

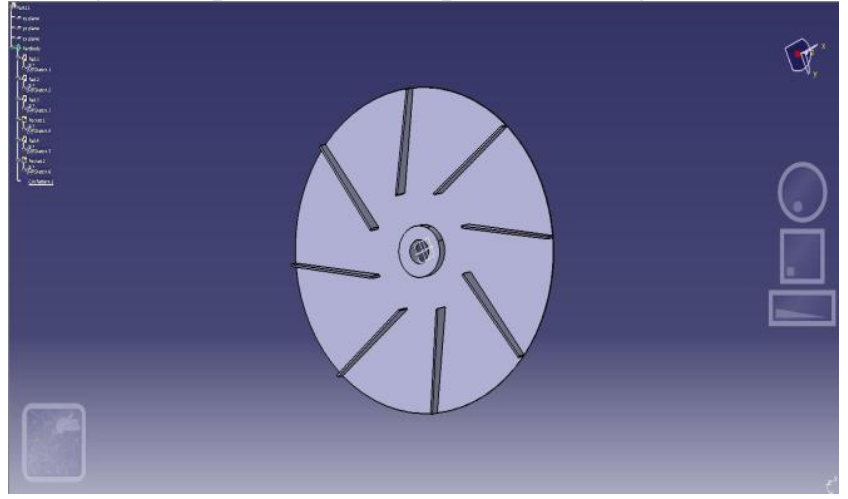

Fig 02: Model of Impeller with 8 blades.

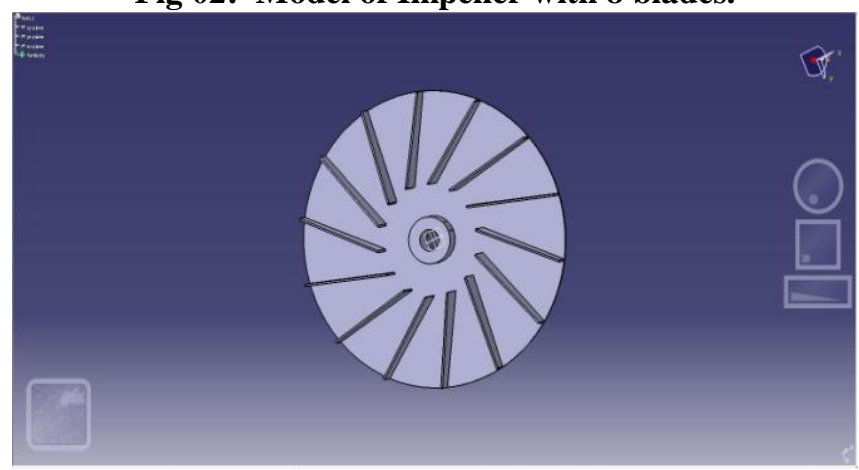

Fig 03: Model of Impeller with 14 blades.

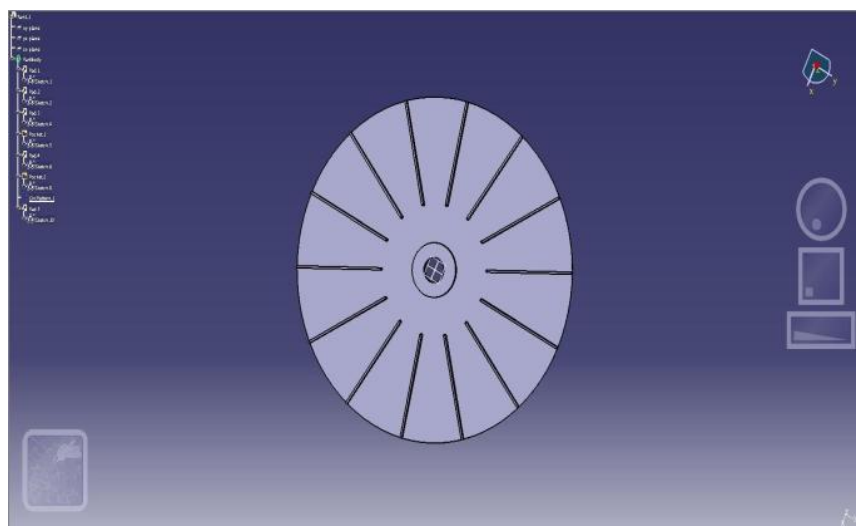

Fig 04: Model of Impeller with 14 blades without blade angle.

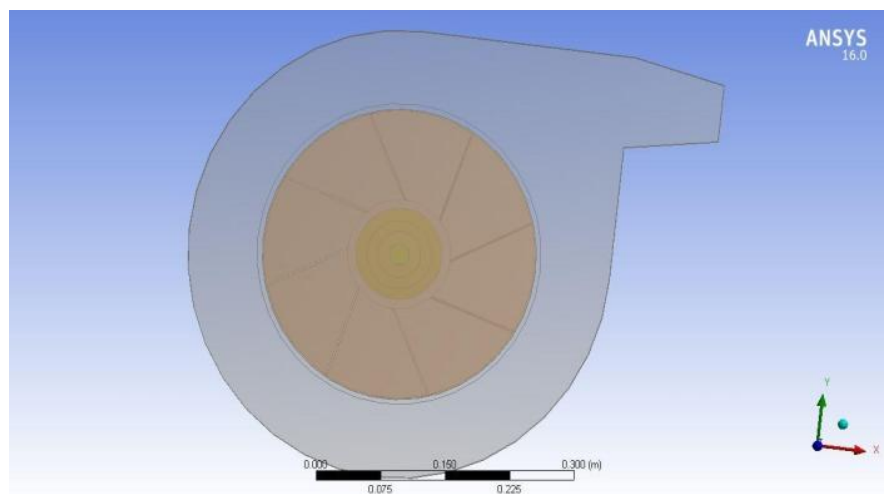

Fig 05: Analysis Model of Impeller with casing.

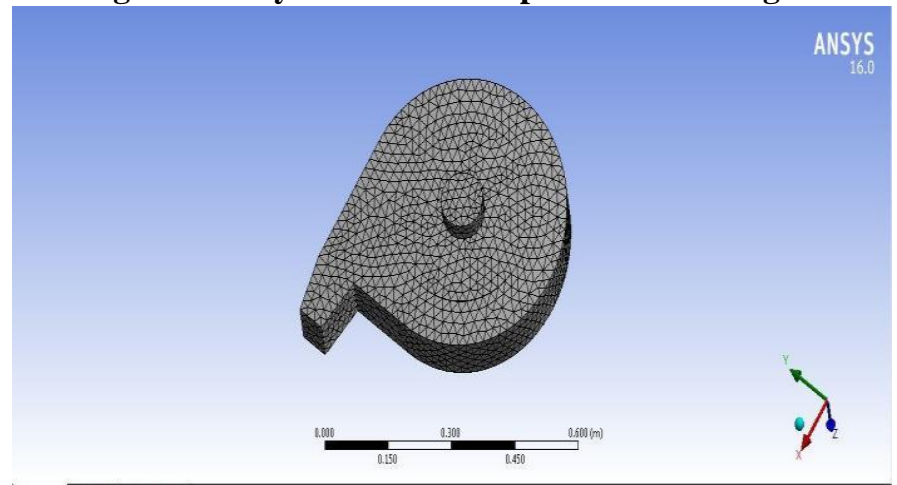

Fig 06: Analysis Model of Impeller with casing.

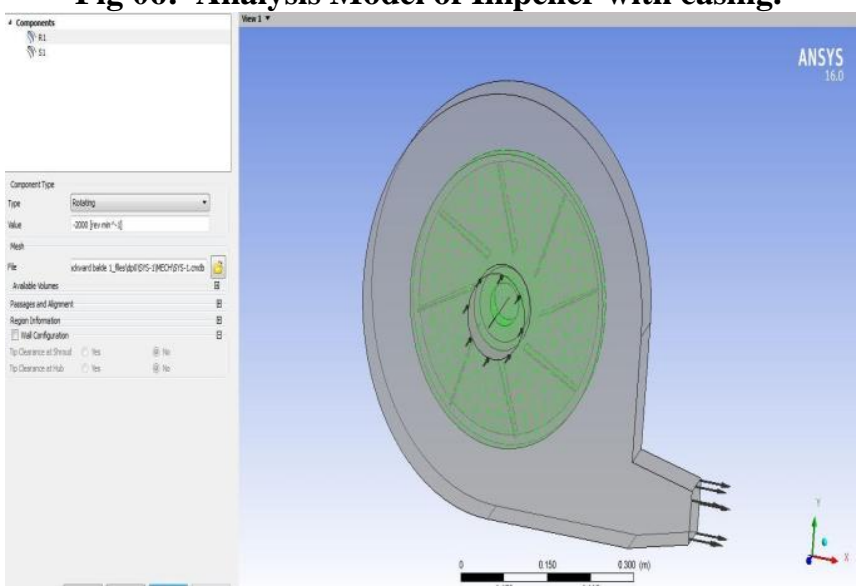

Fig 07: Analysis Model of Impeller with casing.

\section{RESULT AND DISCUSSION}

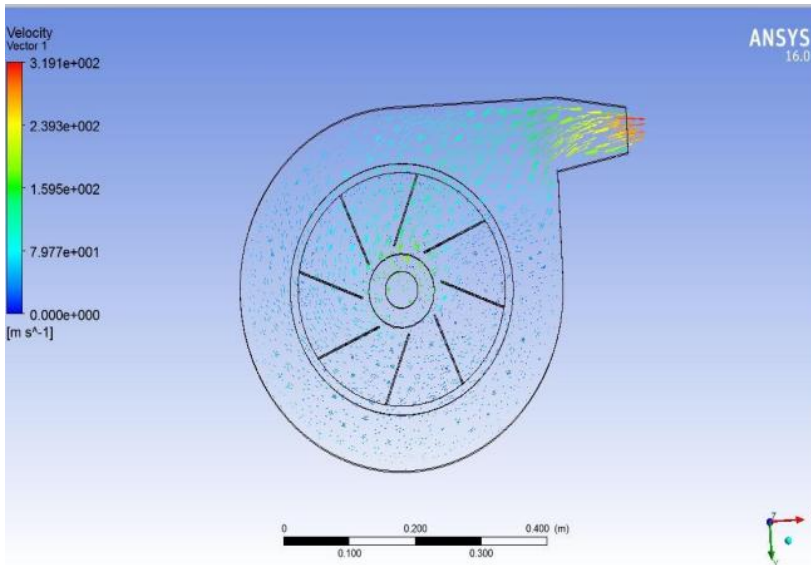

Fig 08: Analysis Model of Impeller with casing

Published By:

Blue Eyes Intelligence Engineering and Sciences Publication

(C) Copyright: All rights reserved.

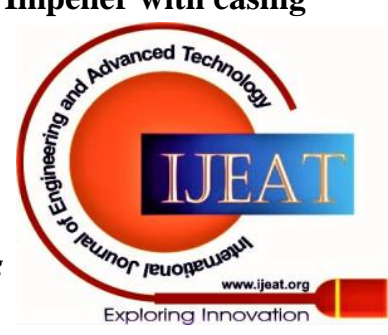




\section{Inspection of Centrifugal Blower by Varying Different Blade Configuration using CFD}

Table- I: Configuration of Impeller with casing 1.

\begin{tabular}{|l|l|}
\hline Speed of Impeller & $2000 \mathrm{rpm}$ \\
\hline Area at outlet & $5.786 \mathrm{~cm}^{\wedge} 2$ \\
\hline Velocity at outlet & $294.85 \mathrm{~m} / \mathrm{sec}$ \\
\hline Discharge(Q) & $0.174 \mathrm{~m} \wedge 3 / \mathrm{sec}$ \\
\hline
\end{tabular}

Forward Blade Model Calculations for 8 Blades:

Speed of Impeller $=2000 \mathrm{rpm}$

Area at outlet $=5.786 \mathrm{~cm}^{\wedge} 2$

Velocity at outlet $=294.85 \mathrm{~m} / \mathrm{sec}$

Discharge $(\mathrm{Q})=0.174 \mathrm{~m} \wedge 3 / \mathrm{sec}$

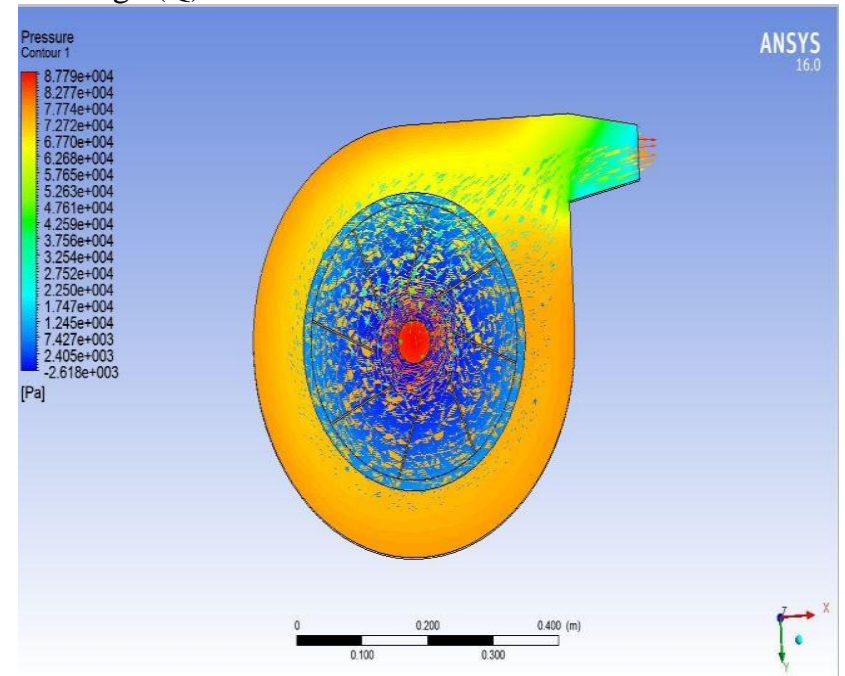

Fig 09: Analysis Model of Impeller with casing

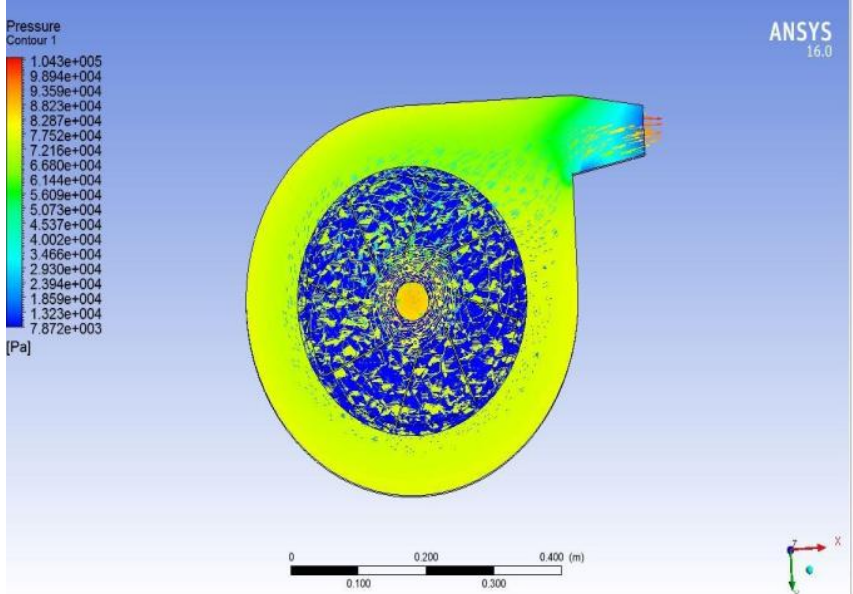

The contents of the journal are peer-reviewed and archival. The journal publishes scholarly articles of archival value as well as tutorial expositions and critical reviews of classical subjects and topics of current interest.

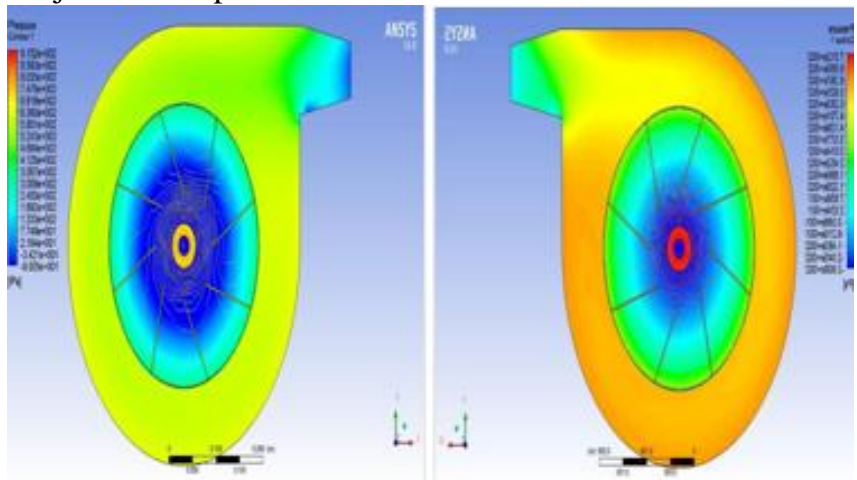

Fig 11: Analysis Model of Impeller with casing
Fig 10: Analysis Model of Impeller with casing

Table- II: Configuration of Impeller with casing 2

\begin{tabular}{|l|l|}
\hline Speed of Impeller & $2000 \mathrm{rpm}$ \\
\hline Area at outlet & $5.816 \mathrm{~cm}^{\wedge} 2$ \\
\hline Velocity at outlet & $29.98 \mathrm{~m} / \mathrm{sec}$ \\
\hline Discharge(Q) & $0.02 \mathrm{~m} \wedge 3 / \mathrm{sec}$ \\
\hline
\end{tabular}

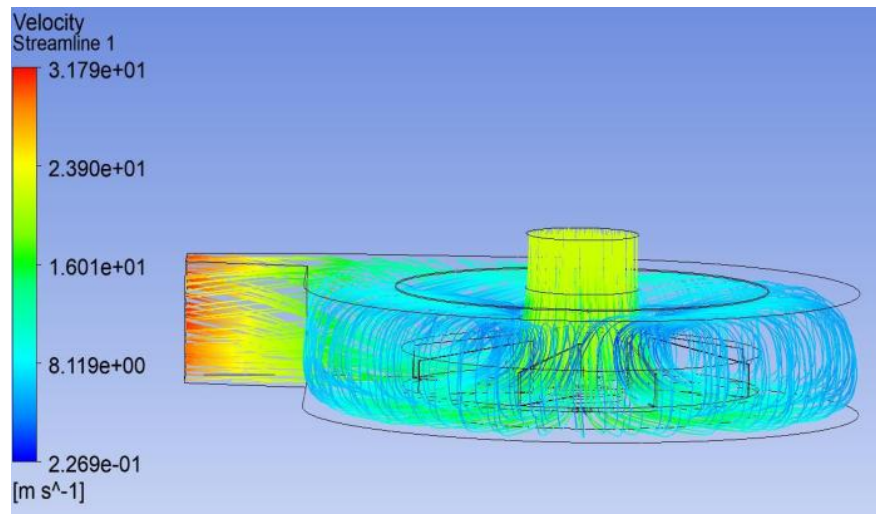

Fig 12: Analysis Model of Impeller with casing

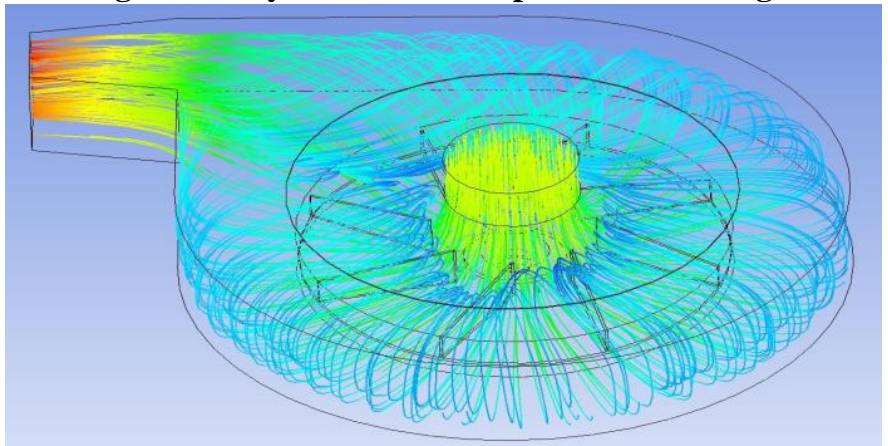

Fig 13: Analysis Model of Impeller with casing

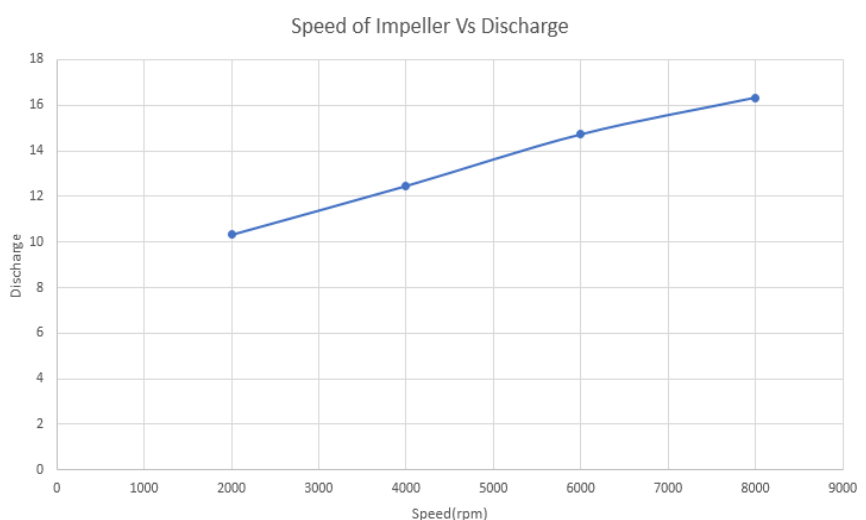

The above diagram shows that when speed of impeller of steadily expanded at that point release likewise get expanded by keeping number of edges consistent and sort of the cutting edge as forward edge.

Release is determined in $\mathrm{m}^{\wedge} 3 / \mathrm{min}$

Speed is being taken in rpm

The perception produced using the chart that as speed of the impeller is expanded from $2000 \mathrm{rpm}$ to $4000 \mathrm{rpm}$ Discharge apparently is addition with little change and variance in the bend, steady increment and skill tendency is seen from $4000 \mathrm{rpm}$ to $8000 \mathrm{rpm}$.

Greatest Discharge is seen at $8000 \mathrm{rpm}$ and least is at 2000rpm to

\section{Published By:}

Blue Eyes Intelligence Engineering

and Sciences Publication

DOI:10.35940/ijeat.A1779.1010120

Journal Website: www.ijeat.org
(C) Copyright: All rights reserved. Exploring Innovation

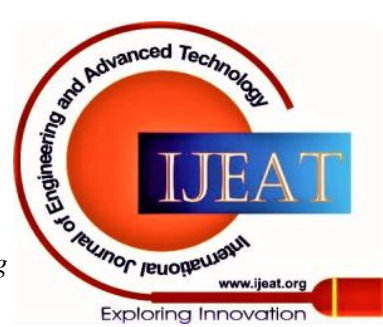




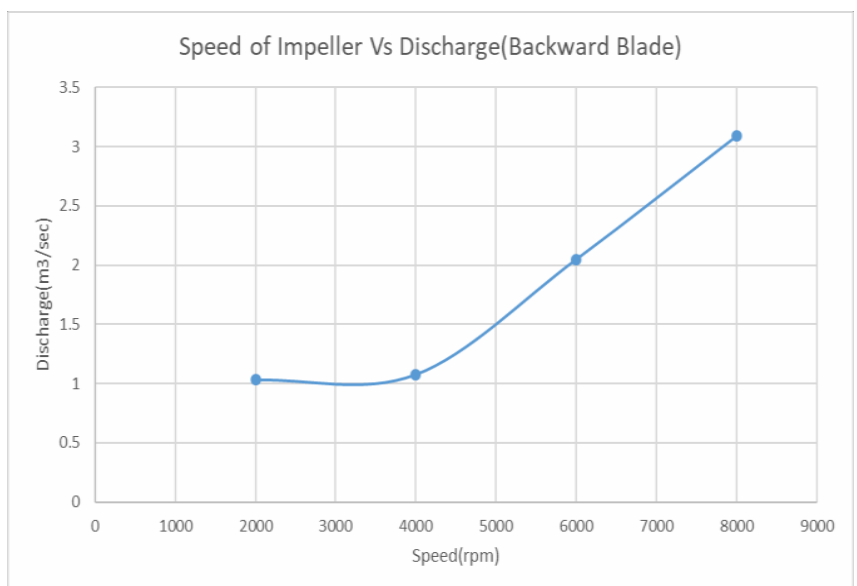

The above diagram shows that when speed of impeller of step by step expanded at that point release likewise gets expanded by keeping number of cutting edges consistent and kind of the edge as in reverse sharp edge. The perception produced using the chart that as speed of the impeller is expanded from $2000 \mathrm{rpm}$ to $4000 \mathrm{rpm}$ Discharge apparently is consistent with little modification and change in the bend, slow increment and skill tendency is seen from $4000 \mathrm{rpm}$ to $8000 \mathrm{rpm}$. Greatest Discharge is seen at $8000 \mathrm{rpm}$ and least is at 2000rpm to 4000rpm

\section{CONCLUSION}

By changing the quantity of fan ribs, the exhibition fluctuates practically nothing. Notwithstanding, the FC fan ribs display the best exhibition in regards to their floe rate reaction and are related with most reduced force.

The weight at the exit is decreased as the stream rate expanded. Among all fans, the FC fan would yield the most noteworthy stream rate.

The recently planned advancement should be returned to and different execution boundaries, for example, impeller thickness, shape and size. Specifically, the state of the impeller would be adjusted to an airfoil type or chamber type.

\section{REFERENCES}

1. Huang Chen-Kang and Hsiech Mu-En, "Performance analysis and optimized design of Backward curved airfoil centrifugal blowers", American society of Heating, Refrigeration and Air Conditioning Engineers, May1,2009

2. J.B. Moreland "Housing Effect of a centrifugal blower" Journal of sound and vibration, Volume 36, isuue 2, September 1974

3. Renjing Cao and Jun HU, "A cluster design approach to noise reduction in centrifugal Blower", International Journal of Ventilation, Volume 3, Number 4,pp.345-352,2005

4. PrezeljJurij and Carudina Mirko, "Identification of noise sources in centrifugal blower with acoustic camera", The JOURNAL OF Acoustical Society of America, Volume 123,Number 5,p,3824,May 2008

5. G.H.Koopmann and W.Neise ," The use of Resonators to silence centrifugal blower", Journal of sound and Vibration, Volume 82,Number 1,pp.17-27,8May 1982

6. Q.Datong et, "Experimental study on the noise reduction of an industrial forward-curved blades centrifugal fan', Applied Acoustics, Volume 70,Number 8,pp.1041-10520,August 2009

7. Christopher L. Banks and Sean F. Wu," Prediction and reduction of Centrifugal blower noises" Journal of Acoustic Society of America, Volume 103, Number 5, pp.3045-3045, May 1998

8. Jianfeng $\mathrm{Ma}$ et al "Noise reduction for centrifugal fan with non-isometric forward -swept blade impeller", Energy power Engineers, Volume 2,Number 4,pp.433-437,2008
9. Young-Tae Lee,Hee-Chang Lim,'Performance assessment of various fan ribs inside a centrifugal blower"School of Mechanical Engineering, Pusan National University, North Korea, November 2015

10. BaymoiNN,HafizAA,OsmanAA,'Energy conserve Manag 2006":47(18):3307-18

11. Chunxi L, Ling WS, Yakui J. The performance of a centrifugal fan with enlarged impeller. Energy Convers Manag 2011;52(8):2902-10

12. Engin T, Gur M, Scholz R. Effects of tip clearance and impelle geometry on the performance of semi-open ceramic centrifugal fan impellers at elevated temperatures. Exp Therm Fluid Sci 2006;30(6):565-77.

13. Cui G, Mandas N, Manfrida N, Nurzia F. Measurements of primary and secondary flows in an industrial forward-curved centrifugal fan. J Fluids Eng 1990;109(4):353-8.

\section{AUTHORS PROFILE}

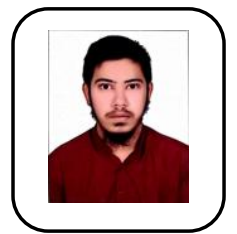

MOHAMMED ASLAM SOHAIL, MTech, Thermal Engineering, Mechanical Department, Gokaraju Rangaraju College of Engineering and Technology, Bachupally, Hyderabad 500090.

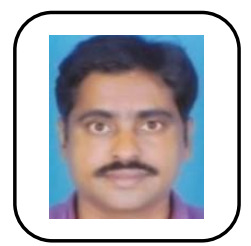

K. VENKATESWARLU, professor of Thermal Engineering, Mechanical Department, Gokaraju Rangaraju College of Engineering and Technology, Bachupally, Hyderabad 500090.

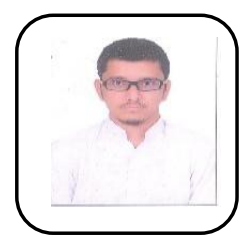

ABDUL HAFEEZ, ME, Mechanica Department, Osmania University, Hyderabad 500007

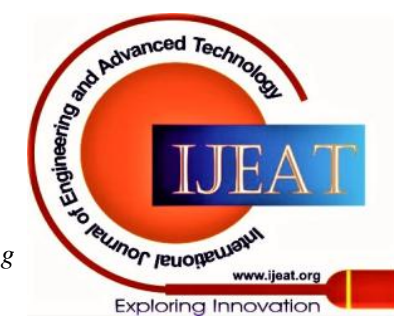

